\title{
sciendo
}

\section{New Energy Policies for Smart Cities - a Comparison among Smart Cities in the European Union}

\author{
Fabrizio D'ASCENZO \\ Sapienza University of Rome, Italy \\ fabrizio.dascenzo@uniroma1.it
}

PICBE

1140

Adrian TANTAU

The Bucharest University of Economic Studies, Bucharest, Romania

adrian.tantau@fabiz.ase.ro

Marco SAVASTANO

Sapienza University of Rome, Italy

marco.savastano@uniroma1.it

\author{
Ana-Maria Iulia ŞANTA \\ The Bucharest University of Economic Studies, Doctoral School of Business Administration, \\ Bucharest, Romania \\ anamaria_iulia_santa@yahoo.com
}

\begin{abstract}
Given the current challenges of climate change our society is dealing with at a global level, the European Union develops a new energy policy based on clean energy. The package "Clean Energy for All Europeans", which has been adopted by the European Commission in 2016, contains measures for a new energy policy at the level of the European Union, based on promoting an Energy Union by following a harmonized framework and common objectives. Considering this European policy debate an interesting topic, the present paper deals with the research question what will be the reaction of the business environment to the energy policy measures proposed by the European Commission in terms of innovation. Indeed, it focuses on innovative solutions based on clean energy, that will arise for achieving the three dimensions of social, economic and environmental sustainability, such as smart cities. The initiative of helping the development of smart cities is currently supported by the European Commission in the project "European Innovation Partnership on Smart Cities and Communities". Innovative measures are related to new financing schemes for the new projects, as new investments are needed for implementing innovative solutions. Case studies from different Member States of the European Union, e.g. Italy, Austria and Romania, will illustrate the concept of smart cities and their development in the European Union allowing for an in depth analysis and comparison among the different business models implemented. The present work presents a mixed method approach based on the combination of both qualitative research methods, such as multiplecase studies and quantitative methods, represented by the analysis and triangulation of data and indicators provided by European institutions. Furthermore, this study presents a multidisciplinary perspective, considering aspects of European policy, European law, business and economics.
\end{abstract}

Keywords: energy policies, smart cities, Clean Energy, Energy Union, innovative solutions in energy, business model, mixed methods.

\section{Introduction}

Cities reflect the life standard of their inhabitants and are therefore in continuous dynamics. At the present moment, big cities and their surroundings concentrate more than $55 \%$ of our planet's population. Due to the annual increase of population in urban areas, it is estimated that the figures will reach 68\% by 2050 (UN 2018). The highest concentration will be registered in Europe, where more than $80 \%$ of the population will 
live by 2020 in urban areas. As a matter of fact, big cities are confronted with new challenges in the building sector and in the transport system and they will play an increasing role for reducing the climate change impact. In the EU, 80\% of the energy consumption will be registered in big cities and their surroundings and therefore a high concentration of $\mathrm{CO}_{2}$ emissions will be registered in these areas (EEA, 2017). The high concentration of $\mathrm{CO}_{2}$ emissions is a major factor determining climate change.

In this context, the energy system and the energy policies have to be reshaped in order to respond to the new demands of big cities in a new, more efficient and sustainable way. The energy structure of cities has to be changed in line with the transition to smart cities.

The aim of this paper is to elaborate an assessment framework for energy policies applied in smart cities, taking into consideration the changes related to smart cities and their continuous development.

Given this process of development at urban level, a new approach is needed in order to design new structures optimizing the energy use in smart cities.

This desiderate is part of the EU policy, which has as a vision to transform the European energy system into the most sustainable in the world. One main contribution of the EU in this field is reflected in the EU Policies for energy savings.

Energy savings are a result of new technologies allowing an increased energy performance, and at the same time they are the result of changes in consumer behavior, changes that are supported by new IT\&C technologies (e.g. smart metering, smart grid, Internet of Things (IoT)).

From an energy policy perspective, an important document is the Energy Performance of Buildings Directive (EPBD) supporting the implementation of smart technologies for buildings in order to increase their energy efficiency (EC, 2018a).

In cities, the building sector has a high energy savings potential, given the fact that these are the largest energy consumers. Within the EU, the building sector is responsible for $40 \%$ of the total energy consumption and for $36 \%$ of $\mathrm{CO}_{2}$ emissions (EC, 2018b). Therefore, the EPBD Directive stipulates that all new buildings must be nearly zero energy buildings by 2020 (https://ec.europa.eu/energy/en/topics/energyefficiency/buildings). This objective is promoting the zero energy buildings, which are defined as buildings which have zero carbon emissions per year.

New technologies contributing to the $\mathrm{CO}_{2}$ reduction in Europe are promoted in the Strategic Energy Technology Plan (SET Plan). The SET Plan is based on the new research and innovation strategy of the EU for low carbon technologies that will contribute to the transition of Europe to a low carbon economy by 2050. This objective was first published by the European Commission in 2011, in the Roadmap for moving to a competitive lowcarbon economy in 2050. This document established clear milestones related to the delivery of a long-term vision: to cut domestic greenhouse gas emissions by at least $80 \%$ by 2050 compared to 1990 .

An important orientation of the SET-Plan is the Smart Cities \& Communities Initiative. This initiative of the European Commission aims to bring together European institutions (like the European Commission), municipalities, stakeholders and companies to cooperate in an interdisciplinary manner to improve life quality in cities. This project supports the Energy Union, which is another recent important project of the European Union, created in the context of the release of the package "Clean Energy for All Europeans" at the initiative of the European Commission. This package proposes a modernization of the energy sector of the European Union by promoting an Energy Union, energy efficiency and renewable energies, achieving thus sustainability. 
The Europe Strategy 20-20-20 promotes the concept of energy efficient cities as a main contributor to an ecological future. The concept of energy efficient city is developed based on the concept of smart cities with the support of IT\&C technologies.

\section{Literature review}

\section{Smart cities - Definitions and Models}

According to the studied literature, a Smart City is a place where the traditional networks and services are made more efficient by using digital and telecommunication technologies, for the benefit of its inhabitants and businesses (Bakıcı et al., T, 2012).

Furthermore, a Smart City is a foundation based on information and communication technology and Internet of things that provide a good quality of service to their citizens through economic and sustainable growth of infrastructure (Aulja et al., 2018, in press).

A smart city is thus a sustainable and efficient urban centre that provides a high quality of life to its inhabitants through optimal management of its resources.

The concept of Smart Cities refers to the optimization of energy use in the building and transport sector and the use of sustainable IC\&T-based solutions (Papastamatiou et al., 2017).

When designing business models for smart cities, the core lies in the utilization of technology for the purpose of improving the quality of life. Energy efficiency and the reduction of emissions are becoming key rationales for smart city investments. From an energy policy perspective, the newest concept is smart energy city (SEC). This is a digital city oriented on sustainable energy systems which are permanent improving their performance (Mosannenzadeh et al., 2017).

Cities have to deal with positive and negative aspects of urbanization related to environmental, social and economic aspects. The United Nations developed 2015 Sustainable Development Goals (SDG) which can be applied as well for the assessment of smart cities. The positive social and economic impact of cities have to be taken into account as well as possible environmental negative effects on the surroundings of cities, as cities are subject to urban dynamics and have the tendency to expand. The Sustainable Development Goals (SDG) elaborated by the United Nations bring the novelty and originality of a holistic approach towards the issue of urban sustainable development (Verma \& Raghubanshi, 2018).

Transport is an important issue in cities, with a high potential to be developed in smart cities. Related to transportation, behavioral changes can be grouped into three categories based on their results: (i) less travel (reduction in total vehicle-distance traveled), (ii) modal shift (users switch to a less energy-intensive mode), and (iii) reduction of per-km energy consumption (fewer stops, faster speed) in the short term (Chen, 2017).

The project of supporting smart cities is a very important topic at European Union level. In this context, the EU Covenant of Mayors for Climate \& Energy brings together thousands of local governments voluntarily committed to implementing EU climate and energy objectives in cities. The Smart Cities Information System (SCIS) provides a lasting repository of information on smart city projects and serves as a knowledge platform to exchange data, experience and know-how. Together with a number of initiatives, the umbrella project of the smart cities policy context is the European Innovation Partnership on Smart Cities and Communities (EIP-SCC). This interdisciplinary effort aims at delivering practical knowledge, capacity-building opportunities, access to financing, finding partners and more, to establish a European smart city market, which helps 
delivering the energy union as well as making European cities the most live able places in the world, thus directly and very practically supporting the aims of the Urban Agenda (EC, 2018a).

The package "Clean Energy for All Europeans" released in November 2016 at the initiative of the European Commission contains proposals for a modernized energy sector at European Union level, with a focus on energy efficiency, on the use of renewable energy, on a better position for the consumer and on transparency (EC, 2017). All these aspects are important elements to be considered when drafting energy policies for smart cities. Documents of the package "Clean Energy for All Europeans" which were 2016 Proposals in the package were adopted by the European Parliament in November 2018 and will soon enter into force with binding legal provisions regarding to the design of the energy sector of the European Union. This applies for the new Energy Efficiency Directive and for the Directive on Renewable Energies, for instance.

Smart cities try to assure a reliable, efficient and low carbon energy supply.

The energy policies for smart cities are related to different specific energy factors that have an important impact on the development of smart cities. One approach for evaluating these factors consists in the identification and in the prioritization of these factors based on the main energy related fields that contribute to the energy systems in smart cities: energy generation, energy storage, grid infrastructure, facilities and transport mobility (Calvillo et al., 2016). In a smart city all these fields are connected through communication, control and hardware devices.

The energy generation field represents a main debate in the EU due to the new Renewable Energy Directive from 2018 and the related new targets for the energy consumption, that stipulate $32 \%$ for energy from renewable sources by 2030 . This objective is a response to the climate change scenarios and the goal to reduce the $\mathrm{CO} 2$ emissions.

Distributed generation is another main factor that will as well redesign the energy systems in smart cities and that will support the development of new renewable energy facilities.

The energy storage field in a smart city enables the integration of renewable energy and the promotion of demand response schemes. Traditional storage systems are represented by different types of batteries or compressed air systems, emerging systems such as Li-ion batteries super.

Smart grid infrastructure uses information and communication technologies for a bidirectional communication among all actors in a thermal or electric energy system. This infrastructure is completed by a smart metering system.

Facilities are represented by commercial and residential buildings, which are a major energy consumer in a smart city. Therefore, the Energy Efficiency Directive from 2018 sets a new energy efficiency target of $32.5 \%$ for 2030 in the EU.

With regard to the buildings sector, in a smart city two main concepts are promoted on a large scale in order to achieve the goals of the "Smart Cities and Communities Initiative": Near-Zero-Energy-Buildings and Zero-Energy-Buildings (European Commission, 2015).

Transport is a main contributor to GHG emissions in cities and an important energy consumer. The trend in the field of city transportation is to replace the gasoline-powered vehicles with biofuel vehicles, electric vehicles or H2-vehicles. Smart mobility is applied for all type of transport users. New communication technologies provide various services for navigation, real time traffic information, smart parking but also for renting bicycles or other transport options (Chen et al., 2017). Initially developed for the transport system, 
smart lighting is more than lighting and includes a broad spectrum of applications such as energy consumption, safety of citizens, data connectivity or new tools for Internet of Things (Petritoli et al, 2019).

\section{Research Methodology}

The methodology of this paper is based on a multi-methods approach. This approach reflects the multi-dimensional research topic of new policies for smart cities, which is related to economic, social and environmental aspects.

First we analyzed relevant materials dealing with the issue of smart cities and energy policies in the context of achieving sustainability for the inhabitants of these urban areas. We have analyzed the research topic of energy policies for smart cities in the studied literature, like books, articles in scientific journals and documents and data published on the websites of European and international institutions dealing with these issues.

Secondly, we developed case studies from different Member States of the European Union, e.g. Italy, Austria and Romania, aiming to illustrate how the concept of smart cities receives a concrete shape in several countries and thus how a policy concept is transformed into a real situation, with an impact on the citizen. These case studies were selected based on criteria like reliable information provided by international rankings and official websites of municipalities and by considering the inspirational attribute of acting as a best practice model for other cities. We have chosen Vienna, Austria for our case-study, as this city was ranked to be the most live able city in 2018 and has thus a very good quality of life. The present article analyzes to what extent the best position in the ranking is correlated to Vienna being a smart city. From Romania, the development of Cluj-Napoca is analyzed in terms of a smart city case study, as Cluj-Napoca is the first city in Romania to become a smart city. For analyzing smart cities in Italy, the Smart City Energy Assessment Framework tool (e-SCEAF), can provide fruitful results for assessing the energy behavior and performance of a city (Papastamatiou et al., 2017). From Italy we have chosen Milano, which aims to be one of the important smart cities in Europe. A comparative approach with an international dimension is used for the assessment of smart cities.

Thirdly, we organized semi-structured and unstructured interviews with major players in the field of smart cities. The results of the questionnaire are analyzed in order to deliver an evaluation of the future development of new policies in smart cities.

Indicators that can be helpful for evaluating smart cities are presented in the table below.

Table 1 The three first indicators of each section from the Municipal Building Level SCEAF

\begin{tabular}{|l|l|}
\hline & 1. Political field of action \\
\hline & $\mathrm{CO}_{2}$ reduction target in municipal buildings till 2020 : \% of total emission \\
\hline & $\begin{array}{l}\text { Energy consumption reduction target in municipal buildings till 2020: \% of } \\
\text { total energy consumption }\end{array}$ \\
\hline $\begin{array}{l}\text { Renewable energy sources in the final use target in municipal buildings till } \\
\text { 2020: \% of total energy consumption }\end{array}$ \\
\hline & 2. Energy and Environmental Profile \\
& $\begin{array}{l}\text { Energy consumption reduction in municipal buildings: \% of energy saved } \\
\text { compared to the benchmark yea }\end{array}$ \\
\hline & Percentage reduction of fossil fuels: \\
\hline
\end{tabular}




\begin{tabular}{|l|l|}
\hline $\begin{array}{l}\text { \% reduction of fossil fuel energy consumption compared to the benchmark } \\
\text { year }\end{array}$ \\
\hline $\begin{array}{l}\text { Average } \mathrm{CO}_{2} \text { emission factor: average emission factor of the building based on } \\
\text { its energy mix }\end{array}$ \\
\hline $\begin{array}{l}\text { 3. Related Infrastructures and ICT } \\
\text { Monitoring Systems, BEMS and BACS: evaluated based on the level of } \\
\text { automation in the building }\end{array}$ \\
\hline & $\begin{array}{l}\text { Energy Monitoring Systems: \% of energy consumption monitored } \\
\text { energy production and temperature }\end{array}$ \\
\hline
\end{tabular}

Based on the above, the Smart City Energy Performance (SCEP) can be evaluated as the weighted sum of the performance of the city on each of the three axis Political Field of Action (PFA), Environmental \& Energy Profiles (EEP) and Related Infrastructures \& ICT (Papastamatiou et al., 2017). The possibility to use the above-mentioned indicators is as well reflected in the evaluation of the concluded interviews.

The research for the present paper outlines the evolution of the European Commission from the stage of Proposals of the package "Clean Energy for All Europeans" released in November 2016 to the actual status of adopted documents that will soon enter into force as EU Directives, like it is the case of the Energy Efficiency Directive and of the Directive on Renewable Energies. The legal provisions with relevance for the new energy policies in smart cities are analyzed and evaluated in the present research article. In order to perform this assessment, documents from the package "Clean Energy for All Europeans" related to the new energy policy of the European Union are analyzed using an interdisciplinary approach. The newest evolutions in terms of European Union energy policy are taken into consideration and evaluated. The present research is therefore new and original, as it focuses on very new topics which are currently debated at European Union level. It represents a contribution to research, as it illustrates these very dynamic current evolutions in the field of European Union energy policy, a field with a high impact both on consumers and on the business environment.

\section{Results and Discussions}

Sustainable urban development finds its concrete expression in creating smart cities within the European Union. Some attributes of smarts cities are the improved quality of life through social interaction and through an easy access to services, minimizing the energy consumption by using green building design technologies, sustainable transport using efficient and clean transport systems, environmental protection, the use of renewable energies and an effective waste management system, the use of clean technologies, ensuring public health, affordable housing, an active role of the community in policy measures (Verma \& Raghubanshi, 2018).

There are therefore two important dimensions to consider when defining and designing a Smart City: on the one side we have to take into consideration the smart efficient use of resources, which means providing good services with the minimum of negative impact on the environment. This can ensure a healthy environment and thus a good life quality for the inhabitants of the Smart City. On the other hand, we have the component of using IT\&C based solutions for improving the life quality in smart cities. Based on advanced algorithm and control techniques, Computational Intelligence and machine learning will enable to think about new optimization levels for the energy systems in a smart city. The new communication technologies and the related 
communication networks and connectivity have to be followed by a new cyber-security design for energy systems in a smart city (O’Dwyer et al, 2019). Supervisory Control and Data Acquisitions (SCADA) Systems will be confronted with new high-level processes for the supervisory management. New security policies for smart cities will as well include the concept of a Safe City (Lacinak \& Ristvej, 2017).

Aspects like biodiversity, energy and air pollution are important elements for the assessment of smart cities. It is a challenge to find the proper indicators to measure the progress achieved by a city in these sectors. This is a difficult task especially due to the fact that different cities have different visions and definitions of sustainability and this makes the concept of sustainability difficult to implement. It generates as well challenges in the application of sustainability indicators in urban areas in a comparative manner.

A great challenge for smart cities is how to measure sustainable development in urban areas. It is a challenge as well to find comparable data about urban sustainable development in order to use it as a basis for policy measures in smart cities. Possible indicators that reflect the sustainability of smart cities could be the following: Environmental Sustainability Index, Environmental Policy Index, Well-being Index, Human Development Index and City Development Index (Verma \& Raghubanshi, 2018).

At the level of the European Union, Eurostat presented the Urban Audit for EU countries as a monitoring framework for sustainability aspects. This tool is based on Eurostat data from yearbooks and it is compiled with the help of national statistics offices. This tool is appropriate for assessing smart cities in the European Union, as it is a Eurostat tool and therefore, we are not confronted with the problem of the lack of comparable data or of a unitary methodology any more (Verma and Raghubanshi, 2018).

The concept of smart cities is reflected in the way cities are designed within the European Union. The present paper illustrates the concept of smart cities in the European Union by presenting some of these smart cities in a comparative manner.

Vienna, the capital of Austria, manages to be, according to international rankings, the most live able city in the world. Vienna is considered to be a smart city and wants to maintain this status. It wants to provide the best quality of life to its inhabitants, to save resources and to use modern and innovative technologies in order to achieve its goals. Vienna defines as goals until 2050 the efficient use of energy, a good energy performance for its buildings, a good mobility achieved with effective use of resources, it aims to be an environment friendly city, with a high rate of social inclusion, with a good education for its inhabitants and with a focus on research, innovation and development (Stadt Wien, 2019). These goals which are in line with the concept of smart cities are taken into consideration by the municipality for drafting development policies for the city.

In Romania, the city of Cluj-Napoca and the city of Alba-Iulia are pilot projects of smart cities, with IT applications, applications on energy efficiency and in transportation. Cluj-Napoca aims to be a smart city. In order to achieve this status, the city focuses on the reduction of pollution and noise, on efficient parking support by technology and on a good public transportation system supported by technology to give accurate information to the users. The city aims to be a clean city, with less pollution and therefore it has as a goal public transportation by means of electric buses.

An appropriate case illustrating the development of smart cities in Italy is the city of Milano, a city that aims to be one of the leading smart cities in Europe. The city of Milano participates in research projects in this field, for example in the project Sharing Cities and it implements policy measures and actions that reflect the energy policy in smart cities (Causone et al, 2017). In this context Milano focuses on the issue of energy efficiency. The measures to be taken include actions in the field of public transportation, of building 
envelopes, public lighting and in the development of energy systems supporting energy efficiency (Causone et al, 2017). Energy smartness is an important component of energy policies in smart cities (Causone et al, 2017) and it would be helpful to have tools to evaluate this aspect in order to be able to compare smart cities in the European Union in terms of the smart use of energy.

The present research analyzed the opinion of experts from various countries related to the topic of smart cities. The results of the interviews with experts from EUcountries like Austria, Germany, Italy and Romania pointed out that environmental aspects are considered to be very important. The reduction of greenhouse emissions is considered to be of very high importance. The importance of effective and efficient use of energy is as well appreciated to be of very high importance. Issues which are as well considered to be of very high importance according to the results of the conducted research are the prevention of pollution, the use of Clean Energy and renewable energies and the saving of resources. All these aspects are considered for drafting new policies for smart cities. An appropriate indicator to reflect the progress of smart cities is according the results of the questionnaire and of the conducted research the Human Development Index.

The Protection of human rights in the EU and the new communication framework in smart cities increase the responsibility regarding the use of data due to new smart systems and big data analysis. Therefore, the new General Data Protection Regulation has to assure a minimum grade of privacy in data collection and analysis (EC, 2018c).

For the policy making level in smart cities, it is important to draft measures according to several criteria of urban development and based on indicators that reflect urban development. These issues will for sure be debated as well in future research projects.

\section{Conclusion}

The development of smart cities is a current issue supported by the European Commission in order to provide a better life quality for the inhabitants of cities in the European Union. It is a new field which will develop in future, as well with the support of European institutions. Further research will thus be needed in this field with an interdisciplinary dimension, where there is currently a research gap. The present paper brings a contribution to a very recent project at European Union level and is therefore an important contribution to the academic world and to research.

Energy policies, which are correlated to the support of smart cities, are currently an important focus of the European Union, which is reflected in the adoption of the new Directives on Energy Efficiency and on Renewable Energies. These Directives include new goals for the energy policy on the European Union, for instance a target of $32.5 \%$ for energy efficiency and a target of 32\% for renewable energy by 2030 .

The field of energy policy is as well correlated with innovation and technology, so that progress in the field of energy technologies and of energy storage will be applied in future when designing smart cities.

One main objective of the energy policies in a smart city has to be the related development of energy fields. New energy policies in smart cities have to find an answer to the integration of hybrid distributed generation systems in the smart energy system. New technologies for batteries, hydro-pumping, $\mathrm{H} 2$ or thermal storage systems will as well represent a main debate for new energy policies in the EU. Other, systems such as supercapacitors of Superconducting Magnet Energy Storage (Colmenar- Santos et al, 2018) may face with high power density energy storage as well in smart cities. 
Smart lighting based on intelligent traffic systems and special parking systems represent optimization solutions for smart cities in order to reduce the energy consumption and the GHG emissions. The development of local mobility in a smart way can be promoted through info-mobility with the goal to promote the use of public transport or bicycle mobility.

The results of this paper can be further developed and they can be used for future research projects that will for sure be needed in the future, given the importance of the debated issue of smart cities at the EU level and the related new energy policies.

\section{References}

Aujla G., Kumar N., Singh M, Zomaya A. (2018) Energy trading with dynamic pricing for electric vehicles in a smart city environment, Journal Parallel Distrib. Comput, in press.

Bakıcı T, Almirall E, Wareham J. A Smart City Initiative: the Case of Barcelona. Journal of the Knowledge Economy. 2012;4(2), 135-148.

Calvillo C, Sánchez-Miralles A., Villar J. (2018) Energy management and planning in smart cities, Renewable and Sustainable Energy Reviews, 55, 273-287.

Causone F., Sangalli A., Pagliano L., Carlucci S. (2017) An exergy analysis for Milano smart city, Energy Procedia 111, 867 - 876.

Chen Y., Ardila-Gomez A., Frame G. (2017) Achieving energy savings by intelligent transportation systems investments in the context of smart cities, Transportation Research Part D, 54, 381-396.

Colmenar-Santos A., Molina-Ibanez E, Rosales-Asensio E, Lopez-Rey A. (2018) Technical approach for the inclusion of superconducting magnetic energy storage in a smart city, Energy 158, 1080-1091.

EC (2018a) Energy and smart cities, https://ec.europa.eu/energy/en/topics/technologyand-innovation/energy-and-smart-cities, accessed 10 December 2018.

EC (2017), https://ec.europa.eu/energy/en/news/new-electricity-market-consumers, accessed on 09.02.2017.

(2018b) Buildings, https://ec.europa.eu/energy/en/topics/energy-efficiency/buildings, accessed on 10 December 2018.

EC (2018c) The General Data Protection Regulation, https://ec.europa.eu/info/law/lawtopic/data-protection/data-protection-eu_en, accessed, 24 January 2019.

EC (2019), http://europa.eu/rapid/press-release_IP-18-6383_en.htm, accessed on 22.01.2019.

EEA (2017) Urban environment, European Environment Agency, http://www.eea.europa.eu/themes/urban/intro, accessed on 20 January 2017.

European Commission (2015) Towards an integrated strategic energy technology (SET) plan: accelerating the European energy system transformation. COMMUNICATION FROM THE COMMISSION C (2015) 6317 final, Brussels.

Eur-Lex, Directive (EU) 2018/2002 OF THE EUROPEAN PARLIAMENT AND OF THE COUNCIL of 11 December 2018 amending Directive 2012/27/EU on energy efficiency, $\quad$ https://eur-lex.europa.eu/legalcontent/EN/TXT/PDF/?uri=CELEX:32018L2002\&from=EN, accessed on 22.01.2019.

Eur-Lex, Directive (EU) 2018/2001 of the European Parliament and of the Council of 11 December 2018 on the promotion of the use of energy from renewable sources, https://eur-lex.europa.eu/legal- 
content/EN/TXT/?uri=uriserv:OJ.L_.2018.328.01.0082.01.ENG\&toc=0J:L:2018:3 28:TOC, http://data.europa.eu/eli/dir/2018/2001/oj, accessed on 22.01.2019.

Kylili A, Fokaides P. (2015) European smart cities: The role of zero energy buildings, Sustainable Cities and Society, 15, 86-95.

Lacinak M, Ristvej J. (2017) Smart city, safety and security. Procedia Engineering, 192, 522-527.

Mosannenzadeh F., Nuccic M., R., Vettorato D. (2017) Identifying and prioritizing barriers to implementation of smart energy city projects in Europe: An empirical approach, Energy Policy 105, 191-201.

O'Dwyer E., Pan I., Acha S., Shah N. (2019) Smart energy systems for sustainable smart cities: Current developments, trends and future directions, Applied Energy 237, 581-597.

Papastamatiou I., Marinakis V., Doukas H., Psarras J. (2017) A decision support framework for smart cities energy assessment and optimization, Energy Procedia, 111, 800 - 809.

Pelau, Corina, Pop, Nicolae Al. (2018). Implications for the energy policy derived from the relation between the cultural dimensions of Hofstede's model and the consumption of renewable energies. Energy Policy, volume 118, pp. 160-168.

Petritoli E, Leccese F, Pizzuti S, Pieroni F. (2019) Smart lighting as basic building block of smart city: An energy performance comparative case study, Measurement 136 (2019) 466-477.

Stadt Wien (2019), https://smartcity.wien.gv.at/site/buergerinnen/, accessed on 18.01 2019.

Smart City Romania Association, http://romaniansmartcity.ro/2017/07/26/clujnapoca-un-viitor-smart-city/, accessed on 18.012019.

Strzelecka A., Ulanicki B., Koop S., Koetsier L., Kees van Leeuwen, Elelman R. (2017) Integrating water, waste, energy, transport and ICT aspects into the smart city concept, Procedia Engineering 186, 609 - 616.

Tanţău, Adrian Dumitru, Nichifor, Maria Alexandra. Consumer Behavior and Perception on the Renewable Energy Instalments. Case Study: Wind Energy in Romania and the Netherlands. $6^{\text {th }}$ International Symposium on Environmental Management and Material Flow Management, www.emfm.tf.bor.ac.rs.

Tantau, Adrian Dumitru, Maassen, Maria Alexandra, Fratila, Laurentiu (2018). Models for Analyzing the Dependencies between Indicators for a Circular Economy in the European Union. Sustainability 2018, 10, 2141, doi:10.3390/su10072141.

UN (2018) 68\% of the world population projected to live in urban areas by 2050, 16 May 2018, New York, https://www.un.org/development/desa/en/news/population/2018-revision-ofworld-urbanization-prospects.html, accessed on 12 December 2018.

Verma, Pramit, Raghubanshi, A.S. (2018). Urban sustainability indicators: Challenges and opportunities. Ecological Indicators volume 93, pp. 282-291. 